\title{
Premature Delivery, CTCAE
}

National Cancer Institute

\section{Source}

National Cancer Institute. Premature Delivery, CT CAE. NCI Thesaurus. Code C143776.

A disorder characterized by delivery of a viable infant before the normal end of gestation.

Typically, viability is achievable between the twentieth and thirty-seventh week of gestation. 